\title{
Assessment of public awareness about body measurements among Fayoum population
}

\author{
Naglaa A. El-Sherbiny ${ }^{1^{*}}$, Mohamed A. Mashahit ${ }^{2}$, Rania E. Sheir ${ }^{3}$ \\ ${ }^{1}$ Public Health Faculty of Medicine Fayoum University, Fayoum, Egypt; *Corresponding Author: naglaahatem@hotmail.com \\ ${ }^{2}$ Internal Medicine Faculty of Medicine Fayoum University, Fayoum, Egypt; mam22@fayoum.edu.eg \\ ${ }^{3}$ Internal Medicine Faculty of Medicine Beni-Suef University, Beni-Suef, Egypt; Rania12@yahoo.com
}

Received 5 December 2013; revised 6 January 2014; accepted 15 January 2014

Copyright (C) 2014 Naglaa A. El-Sherbiny et al. This is an open access article distributed under the Creative Commons Attribution License, which permits unrestricted use, distribution, and reproduction in any medium, provided the original work is properly cited. In accordance of the Creative Commons Attribution License all Copyrights (C) 2014 are reserved for SCIRP and the owner of the intellectual property Naglaa A. El-Sherbiny et al. All Copyright (C 2014 are guarded by law and by SCIRP as a guardian.

\section{ABSTRACT}

The prevalence of obesity is increasing worldwide. There was general agreement that BMI surveillance was an epidemiologic tool for the assessment of obesity in different populations. The aim of this study is to screen community awareness about body measurement, and to examine actual body weight with self-perception of body image. Methods: This study was a community-based survey conducted in Fayoum Governorate. We used multistage stratified random sampling to select the study household with a number of participants (582). We developed a self-administrated structured questionnaire. Anthropometric assessment weight, height and waist circumference were measured, and BMI was calculated. Results: Our results showed that the prevalence of obesity was $\mathbf{8 8 . 7 \%}$ more in female than male. More than half of the participants knew their weight and height. Overall, $\mathbf{4 0 . 6 \%}$ of women and $38.8 \%$ of men misclassified their own weight status by BMI. There was a statistical significant difference between knowing weight and height, and their accurate results $(P=0.000)$. Conclusion: Our results showed that the majority of the Fayoum population was obese. Implementation of health promotion and health education in the community should use effective nutrition education in the mass-media to raise awareness of appropriate body weight and healthy lifestyle.

\section{KEYWORDS}

Obesity; Body Image; Community Awareness

\section{INTRODUCTION}

The prevalence of obesity and overweight is increasing worldwide. It has been called the disease of the Twenty-First century [1]. WHO reports alarming figures for the prevalence of obesity by year 2015 forecasting that there will be 2.3 billion overweight adults, plus more than 700 million obese adults. This is a tragic increase since 2005. At this time, there were approximately 1.6 billion overweight adults and 400 million obese adults [2,3].

WHO data were estimated for adults aged 15 years and the older from 16 countries in the Region and showed the highest levels of overweight and obesity in Egypt, Bahrain, Jordan, Kuwait, Saudi Arabia and United Arab Emirates. The prevalence of overweight and obesity in these countries ranges from $74 \%$ to $86 \%$ in women and $69 \%$ to $77 \%$ in men [4]. Egypt is the 14 th fattest country in the world, according to (WHO, 2010) [5].

Overweight and obesity are defined as abnormal or excessive fat accumulation that presents a risk to health. Overweight and obesity are the fifth leading risk for global deaths. At least 2.8 million adults die each year as a result of being overweight or obese. Obesity is among the leading modifiable behavior risks for morbidity, mortality and disability [6].

Body Mass Index (BMI) has probably become the most common indicator used to assess overweight and obesity in a wide variety of settings, including clinical, public health, and community-based programs [7]. There was general agreement that BMI surveillance was a sound epidemiologic tool for the assessment of overweight and obesity in populations. It can be used to increase community awareness of need and to focus their attention on the importance of weight management [8]. The International Obesity Task Force (IOTF) cut points 
linked BMIs of $25 \mathrm{~kg} / \mathrm{m}^{2}$ (adult overweight) and 30 $\mathrm{kg} / \mathrm{m}^{2}$ (adult obesity) at age 18.0 years and above $[9,10]$.

Community-based programs and educational strategies are designed to reach people outside of traditional health care settings. Using non-traditional settings can help to encourage informal information sharing within communities through peer social interaction. Reaching out to people in different settings also allows for greater tailoring of health information and education [11].

For a community to improve its health, its members must often change aspects of the physical, social, organizational, and even political environments in order to eliminate or reduce factors that contribute to health problems or to introduce new elements that promote better health [12].

Our primary goals were to explore level of community awareness about body measurement, assess prevalence of obesity among the Fayoum population, and examine actual body weight with self-perception of body image.

\section{SUBJECTS AND METHODS}

This study was a community-based research related to body measurement awareness because it is very important to detect the perception of individual to his body image, as this is the first step for problem solution is to be aware that there was a problem related to health status of the individuals. The study was a cross-sectional descriptive observational survey conducted in Fayoum Governorate, a developing city in Middle Egypt. We used multistage stratified random sampling to select the study household. In the first stage, the governorate was divided into 6 districts: (Fayoum, Etsa, Tamiya, Sinnuris, Youssef Sadiek, Abshoay). We choose Fayoum district because it has both an urban and rural population as it is surrounded by villages. Fayoum district population is estimated of 566; 164 inhabitants, according to (CAPMAS, 1996) [13]. Thus, they represent $5.28 \%$ of the total population of the province. In the second stage, two regions were selected Mansiat Abdallah and Mansiat Lotfallah based on the adjacent geographic location and they represent a rural and urban community. In the third stage two main streets were selected. In the fourth stage, the households were chosen by random sample in the chosen streets.

A study was carried among the population who were aged $\geq 16$ years in the chosen households. A simple questionnaire was conducted on a random sample of 582 participants. A pre-designed structured questionnaire was used to collect the information regarding the socio-demographic profile of the population and their awareness about their weight, height and body mass index and waist circumference as a tool for detection of obesity. Anthropometric assessment was carried out according to Jelliffe (1966) [14]; weight, height and waist circumference were measured and BMI was calculated according to the following formula (Quetelet, 1830 to 1850): BMI = weight (kg)/height (m) 2. Weight: the participant was weighed wearing light cloths and without shoes, using digital balance. Height: was measured with the subject's head in the Frankfort plane and without shoes to the nearest $0.1 \mathrm{~cm}$; waist circumference: just above the pelvic bony (prominences) landmarks.

The following cut off values of BMI of 30 or more is generally considered obese and BMI equal to or more than 25 is considered overweight. As regards the waist circumference which is used to assess the abdominal obesity the cut off values for women: WC $>88 \mathrm{cms}$ and WC > $102 \mathrm{cms}$ for men [15].

\subsection{Statistical Analysis}

Data Management: Data were collected, coded and analyzed using Statistical Package for Social Science (SPSS) software version 18 (SSPS, Chicago, IL). The prevalence was expressed in percentage. In addition to descriptive statistics, non-parametric tests (chi-square) were used to find its association with other factors. P $\leq$ 0.05 was considered statistically significant.

\subsection{Ethical Considerations}

This study was reviewed and approved by the Faculty of Medicine Research Ethical Committee, and a waiver of the consent form was approved. We used an anonymous questionnaire with no private or sensitive information. Before distributing the questionnaire, the researcher informed the participants about the objectives of the study, and the confidentiality of their information. Verbal consent was obtained prior to participation. Anthropometric measurements were conducted in a private place. All participants had the right not to participate in the study.

\section{RESULTS}

The socio-demographic profile of the participants is given in Table 1. The participants' age range from 16 - 60 years with a mean age of $32.97 \pm 10.72$ years with a domination of female gender distribution across male as (58.8\% females and $41.2 \%$ males). They urban residency was $55.8 \%$ and $52.8 \%$ were a high educated participant and occupation was almost equally distributed between the categories (professional, administrative, student and no work).

Awareness of participants about their own weight, height, Body Mass index (BMI) and waist circumference (WC): the results shown in Table 2 revealed that more than half of the participants knew their weight and height (56.0\%; 50.9\% respectively). Only $(42.1 \%$; $26.5 \%$ respectively) knew about (BMI) and (WC) as an indicator 
Table 1. Socio-demographic characteristics of the participants.

\begin{tabular}{|c|c|c|}
\hline Variables & $N=582$ & Percent \\
\hline \multicolumn{3}{|c|}{ Age } \\
\hline Below 20 & 83 & 14.2 \\
\hline $20-40$ & 342 & 58.8 \\
\hline$+40-60$ & 157 & 27.0 \\
\hline \multicolumn{3}{|c|}{ Sex } \\
\hline Male & 240 & 41.2 \\
\hline Female & 342 & 58.8 \\
\hline \multicolumn{3}{|c|}{ Residency } \\
\hline Urban & 325 & 55.8 \\
\hline Rural & 257 & 44.2 \\
\hline \multicolumn{3}{|c|}{ Education } \\
\hline Primary education & 91 & 15.6 \\
\hline Secondary education & 176 & 30.2 \\
\hline High education & 315 & 54.2 \\
\hline \multicolumn{3}{|c|}{ Occupation } \\
\hline Professional & 147 & 25.3 \\
\hline Administrative & 165 & 28.4 \\
\hline Student & 151 & 25.9 \\
\hline No work & 119 & 20.4 \\
\hline
\end{tabular}

Table 2. Participants awareness about knowing weight, height, BMI and WC.

\begin{tabular}{|c|c|c|c|c|c|c|c|}
\hline \multirow{2}{*}{ Variables } & \multicolumn{2}{|c|}{ Male $=240$} & \multicolumn{2}{|c|}{ Female $=342$} & \multicolumn{2}{|c|}{ Total $=582$} & \multirow{2}{*}{ P value } \\
\hline & N. & $\%$ & N. & $\%$ & N. & $\%$ & \\
\hline \multicolumn{8}{|c|}{ Know weight } \\
\hline Yes & 197 & 82.1 & 129 & 37.7 & 326 & 56.0 & \multirow{2}{*}{$0.000^{*}$} \\
\hline No & 43 & 17.9 & 213 & 62.3 & 256 & 44.0 & \\
\hline \multicolumn{8}{|c|}{ Know height } \\
\hline Yes & 176 & 73.3 & 120 & 35.1 & 296 & 50.9 & \multirow{2}{*}{$0.000^{*}$} \\
\hline No & 64 & 26.7 & 222 & 64.9 & 286 & 49.1 & \\
\hline \multicolumn{8}{|c|}{ BMI } \\
\hline Yes & 122 & 50.8 & 123 & 36.0 & 245 & 42.1 & \multirow{2}{*}{$0.000^{*}$} \\
\hline No & 118 & 49.2 & 219 & 64.0 & 337 & 57.9 & \\
\hline \multicolumn{8}{|c|}{ WC } \\
\hline Yes & 78 & 32.5 & 76 & 22.2 & 154 & 26.5 & \multirow{2}{*}{$0.004^{*}$} \\
\hline No & 162 & 67.5 & 266 & 77.8 & 428 & 73.5 & \\
\hline
\end{tabular}

of obesity. There was a difference in awareness about body measurement as males were more aware about their body measurement than females with a highly statistical significant difference between them $(P=0.000,0.000$, $0.000,0.004)$. As regards the relation between knowing weight and accurate weight numbers only 152 (46.6\%) are known their accurate weight with a significant statistical difference $(\mathrm{P}=0.000)$ and from (296) participants documented that they know their height, only 100 (33.8\%) reported the accurate height with a significant statistical difference between them $(\mathrm{P}=0.000)$.

Table 3 showed that the prevalence of obesity was $(88.7 \%)$ by the BMI measure which is in contrast with the participant self-image as only (49\%) of them see themselves as obese, and (13.4\%) see themselves as underweight. Regarding the relation between BMI and waist circumference 156 (30.2\%) of the obese participants were at risk for different diseases as their waist circumference was above the normal average

Awareness of participants about their body image: the results shown in Table 4 revealed that there was a statistically significant difference $(\mathrm{P}=0.000)$ between body image and the BMI. As (87.7\%) of the participants selfreported as normal was obese by the BMI, and $(65.4 \%$ of the self-reported underweight is considered obese by the BMI.

Table 5 revealed that there were no significant association noted between the body self-image and age categories, residency, educational status, occupation with a $(\mathrm{P}$ value $=0.751,0.537,0.192,0.788$ ) respectively .

Regarding the different gender in the study population, a significant association was found between them as

Table 3. Comparison between personal body image and BMI.

\begin{tabular}{ccccc}
\hline \multirow{2}{*}{ Variables } & \multicolumn{2}{c}{ Body Image } & \multicolumn{2}{c}{ BMI } \\
\cline { 2 - 5 } & $\mathrm{N}$ & $\%$ & $\mathrm{~N}$ & $\%$ \\
\hline Normal & 219 & 37.6 & 66 & 11.3 \\
Obese & 285 & 49.0 & 516 & 88.7 \\
Underweight & 78 & 13.4 & 0 & 0 \\
Total & 582 & 100.0 & 582 & 100.0 \\
\hline
\end{tabular}

Table 4. Relation between Self-image and BMI.

\begin{tabular}{cccccccc}
\hline & \multicolumn{6}{c}{ Body-Image } & \\
\cline { 2 - 6 } BMI & \multicolumn{2}{c}{ Normal } & \multicolumn{2}{c}{ Obese } & Underweight & P value \\
\cline { 2 - 6 } & N. & \% & N. & \% & N. & \% & \\
\hline Normal & 27 & 12.3 & 12 & 4.2 & 27 & 34.6 & \\
Obesity & 192 & 87.7 & 273 & 95.8 & 51 & 65.4 & $\mathbf{0 . 0 0 0}^{*}$ \\
Total & 219 & 100 & 285 & 100 & 78 & 100 & \\
\hline
\end{tabular}


knowing their accurate weight, height $(P=0.000,0.000)$. Also there were a statistical significant difference of $\mathrm{BMI}$ and WC (P = 0.027 and 0.000$)$ respectively. However there was no association between male and female regarding body self-image $(\mathrm{P}=0.582)$ as shown in Table 6.

\section{DISCUSSION}

Obesity is now described as an epidemic and considered to be a major public health problem [16]. The prevalence of obesity in United States continues to be high; more than 35\% of U.S. men and women were obese in 2009-2010 [17]. The WHO estimates that currently around one in every three of the world's adults is overweight, while nearly one in every ten is obese. With nearly $70 \%$ of its adult population overweight or obese [18].

Our study was conducted in Fayoum districts and concerns 582 participants with a mean age was $32.97 \pm$ 10.72 years and female was (58.8\%) and (41.2\%) males and they were nearly equally distributed between urban and rural areas with a 52.8\% were a higher educated participants Table 1. Regarding participants awareness about their own weight, height, and knowing the (BMI) and (WC) as an indicators for estimation of obesity: our

Table 5. Relation between Body image and demographic factors.

\begin{tabular}{|c|c|c|c|c|c|c|c|}
\hline \multirow{2}{*}{ Variables } & \multicolumn{2}{|c|}{ Normal } & \multicolumn{2}{|c|}{ Obese } & \multicolumn{2}{|c|}{ Underweight } & \multirow{2}{*}{$P$ value } \\
\hline & N. & $\%$ & N. & $\%$ & N. & $\%$ & \\
\hline \multicolumn{8}{|c|}{ Age } \\
\hline Below 20 & 31 & 14.2 & 42 & 14.7 & 10 & 12.8 & \multirow{3}{*}{0.751} \\
\hline $20-40$ & 129 & 58.9 & 162 & 56.8 & 51 & 65.4 & \\
\hline$+40-60$ & 59 & 26.9 & 81 & 13.9 & 17 & 21.8 & \\
\hline \multicolumn{8}{|c|}{ Residency } \\
\hline Urban & 120 & 54.8 & 165 & 57.9 & 40 & 51.3 & \multirow{2}{*}{0.537} \\
\hline Rural & 99 & 45.2 & 120 & 42.1 & 38 & 48.7 & \\
\hline \multicolumn{8}{|c|}{ Education } \\
\hline Primary education & 41 & 18.7 & 34 & 11.9 & 16 & 20.5 & \multirow{3}{*}{0.192} \\
\hline Secondary education & 65 & 29.7 & 88 & 30.9 & 23 & 29.5 & \\
\hline High education & 113 & 51.6 & 163 & 51.7 & 39 & 50 & \\
\hline \multicolumn{8}{|c|}{ Occupation } \\
\hline Professional & 57 & 26.0 & 69 & 24.2 & 21 & 26.9 & \multirow{4}{*}{0.788} \\
\hline Administrative & 69 & 31.5 & 77 & 27.0 & 19 & 24.4 & \\
\hline Student & 54 & 24.7 & 77 & 27.0 & 20 & 25.6 & \\
\hline No work & 39 & 17.8 & 62 & 21.8 & 18 & 23.1 & \\
\hline
\end{tabular}

Table 6. Sex distribution regarding accurate weight, height, $\mathrm{BMI}$ and WC.

\begin{tabular}{|c|c|c|c|c|c|c|c|}
\hline \multirow{2}{*}{ Variables } & \multicolumn{2}{|c|}{ Male $=240$} & \multicolumn{2}{|c|}{ Female $=342$} & \multicolumn{2}{|c|}{ Total $=582$} & \multirow{2}{*}{$P$ value } \\
\hline & N. & $\%$ & N. & $\%$ & N. & $\%$ & \\
\hline \multicolumn{8}{|c|}{ Accurate weight } \\
\hline Accurate & 96 & 40.0 & 63 & 18.4 & 159 & 27.3 & \multirow{2}{*}{$0.000^{*}$} \\
\hline Not accurate & 144 & 60.0 & 279 & 81.6 & 423 & 72.7 & \\
\hline \multicolumn{8}{|c|}{ Height } \\
\hline Accurate & 69 & 28.8 & 31 & 9.1 & 100 & 17.2 & \multirow{2}{*}{$0.000^{*}$} \\
\hline Not accurate & 171 & 71.3 & 311 & 90.9 & 482 & 82.8 & \\
\hline \multicolumn{8}{|c|}{ BMI } \\
\hline Normal & 35 & 14.6 & 31 & 9.1 & 66 & 11.3 & \multirow{2}{*}{$0.027^{*}$} \\
\hline Obese & 205 & 85.4 & 311 & 90.9 & 516 & 88.7 & \\
\hline \multicolumn{8}{|c|}{ WC } \\
\hline Normal & 199 & 82.9 & 227 & 66.4 & 426 & 73.2 & \multirow[b]{2}{*}{$0.000^{*}$} \\
\hline At risk & 41 & 17.1 & 115 & 33.6 & 156 & 26.8 & \\
\hline \multicolumn{8}{|c|}{ Body Image } \\
\hline Normal & 91 & 37.9 & 128 & 37.4 & 219 & 37.6 & \\
\hline Obesity & 113 & 47.1 & 172 & 50.3 & 285 & 49.0 & 0.582 \\
\hline Underweight & 36 & 15.0 & 42 & 12.3 & 78 & 13.4 & \\
\hline
\end{tabular}

results shown in Table 2 revealed that more than half of the participants knew their weight and height $(56.0 \%$; $50.9 \%$ respectively) and (42.1\%; 26.5\% respectively) knew about (BMI) and (WC) with a highly statistical significant difference between different gender as $(\mathrm{P}=$ $0.000,0.000,0.000,0.004)$ this is explained as $73 \%$ of the participants were below the age of 40 and more than half of the participants were highly educated so they were interested by knowing their weight and height and caring about their self-image. In contrast to the modern Western cultural and popular media which pressure on women to be thin, Fayoum culture preferring the overweight woman this is mainly referred to their agriculture community, that they need woman with a good body building to help them in work and be able to caring about their kids and house work. There was a statistical significant difference between knowing weight and height, and their accurate results $(\mathrm{P}=0.000)$.

Virginia et al., (2003) [19] reported that although selfperception of weight status appeared highly sensitive to small changes in BMI, a large percentage of men (29.8\%) and women $(27.5 \%)$ placed themselves in a weight category that is incongruent with public health classifications. 
With respect to self-perceived weight status, most women were in the "overweight" category (62.3\%), while most men were in the "about the right weight" category (48.9\%). This result was in agreement with our study results as (87.7\%) of the participants self-reported as normal was obese by the BMI, and $(65.4 \%$ of the self-reported underweight is considered obese by the BMI. However, there was no association between male and female regarding body self-image $(\mathrm{P}=0.582)$ Table 4 $[20,21]$.

The overall prevalence of obesity in our study was (88.7\%) higher in female (90.9\%) than male (85.4\%) Table 6 which is in agreement with the WHO report (2013) and (James et al., 2004) [2,4] that documented a higher prevalence of obesity among adult women, while overweight is more marked among adult men. This is because of major changes in life style in the past few decades [22]. In Egypt, rising obesity rates are connected to a growing number of "junk food" and fast food outlets, coupled with increasingly sedentary lifestyles.

The problem of obesity is inherently complex, and no single strategy has been determined most effective. Obesity should be addressed through a comprehensive approach across multiple settings and sectors that can change individual nutrition and physical activity behaviors and the environments and policies that affect these behaviors [23]. Changes might include: Instituting new programs, policies, and practices, changing community attitudes, beliefs, or social norms [12].

Health awareness turned out an essential mediator, which helps to promote a weight-stabilizing life-style. In order to raise health awareness; and motivate people at risk to undergo a life-style modification. There is a need for health education activity regarding obesity and its risk factors to promote healthy life style among community. Target groups should be informed about the better health status in normal weight compared with that in overweight and obese people. The mission of the Healthy People 2020 strives to increase public awareness and understanding of the determinants of health, disease, and disability, and the opportunities for progress [24].

\section{CONCLUSION \& RECOMMENDATION}

It was clear that the prevalence of obesity in Fayoum population was high (88.7\%). Also there was incorrect self-image about obesity regarding both male and female. These findings are important for public health interventions in obesity care. Public awareness about obesity, its risk factors and complication is an important determinant, and awareness needs to be increased. Implementation of health promotion and health education in the community should use effective nutrition education and incorporating positive messages in the mass-media programs to raise awareness of appropriate body weight to combat the growing level of obesity.

\section{REFERENCES}

[1] Rössner, S. (2002) Obesity: The disease of the twentyfirst century. International Journal of Obesity, 26, S2-S4. http://dx.doi.org/10.1038/sj.ijo.0802209

[2] WHO (2013) Regional Office for the Eastern Mediterranean site-Health Topic-Obesity.

[3] Musaiger, A.O. (2004) Overweight and obesity in the Eastern Mediterranean Region: can we control it? Eastern Mediterranean Health Journal, 10, 789-793.

[4] James, W.P.T., Jackson-Leach, R. and NiMhurchu, C. (2004) Overweight and obesity (high body mass index). In: Ezzati, M., Lopez, A., Rodgers, A., et al., eds., Comparative Quantification of Health Risks: Global and Regional Burden of Disease Attributable to Selected Major Risk Factors, World Health Organization, Geneva, 497-596.

[5] WHO (2010) Framework for the implementation of global strategy on diet, physical activity and health in the eastern Mediterranean region.

[6] Mokdad, A.H., Marks, J.S., Stroup, D.F. and Gerberding, J.L. (2004) Actual causes of death in the United States, 2000. JAMA, 291, 1238-1245. http://dx.doi.org/10.1001/jama.291.10.1238

[7] John, H.H. (2009) Challenges of accurately measuring and using BMI and other indicators of obesity in children. Pediatrics, 124, S3-S22.

[8] William, H.D., Mary, T.S. and Laura, C.L. (2009) Issues and implications of screening, surveillance, and reporting of children's BMI. Pediatrics, 124, S98-S101.

[9] David, S.F. and Bettylou, S. (2009) The validity of BMI as an indicator of body fatness and risk among children. Pediatrics, 124, S23-S34.

[10] Cole, T.J., Bellizzi, M.C., Flegal, K.M. and Dietz, W.H. (2000) Establishing a standard definition for child overweight and obesity worldwide: International survey. BMJ, 320, 1240-1243.

http://dx.doi.org/10.1136/bmj.320.7244.1240

[11] Gamm, L., Castillo, G. and Williams, L. (2004) Education and community-based programs in rural areas: A literature review. In: Gamm, L. and Hutchison, L., Eds., Rural Healthy People 2010: A companion document to Healthy People 2010, Volume 3, The Texas A\&M University System Health Science Center, School of Rural Public Health, Southwest Rural Health Research Center, College Station, 167-186.

http://www.srph.tamhsc.edu/centers/rhp2010/Volume_3/V ol3Ch4LR.pdf

[12] Institute of Medicine (2003) The future of the public's health in the 21st century. National Academies Press, Washington DC.

[13] CAPMAS (1996) Central Agency for Public Mobilization and Statistics (CAPMAS), Cairo.

[14] Jelliffe, D.B. (1966) The assessment of the nutritional status of the community. World Health Organization Monograph, Series No. 53, Geneva, 50-84. 
[15] Rana, M.A.K. and Maaz, A. (2010) To assess the public awareness about obesity among adult populace of Lahore. http://pjmhsonline.com/to_assess_the_public_awareness_ a.htm

[16] Mokdad, A.H., Bowman, B.A., Ford, E.S., Vinicor, F., Marks, J.S. and Koplan, J.P. (2001) The continuing epidemics of obesity and diabetes in the United States. JAMA, 286, 1195-200. http://dx.doi.org/10.1001/jama.286.10.1195

[17] Flegal, K. (2012) Prevalence of obesity in the United States, 2009-2010. NCHS Data Brief: CDC.

[18] WHO (2011) Regional strategy on nutrition 2010-2019 and plan of action in Eastern Mediterranean region.

[19] Virginia W, Chang, Nicholas A, Christakis MPH. (2003) Self-Perception of Weight Appropriateness in the United States. American Journal of Preventive Medicine, 24, 332-339.

[20] Agrawal, P., Gupta, K., Mishra, V. and Agrawal, S. (2013) A study on body-weight perception, future intention and weight-management behavior among normal-weight, overweight and obese women in India. Public Health $\mathrm{Nu}$ trition, 8, 1-12.

http://dx.doi.org/10.1017/S1368980013000918

[21] Cynthia, L.O., Carroll, D.M., Kit, B.K. and James, M.W.P.T. (2004) Overweight and obesity (high body mass index). In: Ezzati, M., et al., Eds., Comparative Quantification of Health Risks: Global and Regional Burden of Disease Attributable to Selected Major Risk Factors, World Health Organization, Geneva, 497-596.

[22] Blanchini, F., Kaaks, R. and Vainio, H. (2002) Overweight, obesity and cancer risk. The Lancet Oncology, 3, 566574.

[23] Sherry, B., Blanck, H.M., Galuska, D.A., Pan, L., Dietz, W.H. and Balluz, L. (2010) Vital signs: State-specific obesity prevalence among adults-United States, 2009. Morbidity \& Mortality Weekly Report, 59, 951-955.

[24] United States Department of Health and Human Services (HHS) (2011) Healthy People 2020.

\section{ABBREVIATION LIST}

WHO: World Health Organization

BMI: Body Mass Index

WC: Waist Circumference

IOTF: The International Obesity Task Force

CAPMAS: Central Agency for Public Mobilization and

Statistics

SPSS: Statistical Package for Social Science 